\title{
Asociación de Crepidula coquimbensis con Pagurus edwardsi: efecto sobre el potencial de dispersión y diferenciación genético poblacional
}

Association of Crepidula coquimbensis with Pagurus edwardsi: effect on dispersal potential and population genetic structure

\begin{abstract}
Carlos Vilches ${ }^{1}$, Julio Pradenas ${ }^{1}$, Adriana Quiñones ${ }^{1}$ y Antonio Brante ${ }^{1}$
${ }^{1}$ Departamento de Ecología, Facultad de Ciencias, Universidad Católica de la Santísima Concepción, Casilla 297, Concepción, Chile. abrante@ucsc.cl

Abstract.- Crepidula coquimbensis is a protandric marine gastropod with direct development and restricted mobility, which only inhabits inside of empty shells of other marine gastropods cohabiting with hermit crabs of the genus Pagurus. In this study, we report potential dispersal mechanisms of $C$. coquimbensis and the effect on its population genetic distance and structure, using the gene COI, in three localities of northern Chile. The results suggested that $C$. coquimbensis shows high levels of genetic differentiation at local scale, and the association with $P$. edwardsi would be its only one mechanism of dispersal.
\end{abstract}

Key words: Life history, marine gastropod, protandrism, hermit crab

\section{INTRODUCCIÓN}

En los invertebrados marinos, el modo de desarrollo embrionario ha sido descrito como uno de los principales caracteres que se relaciona con el potencial de dispersión (Weersing \& Toonen 2009, Kelly \& Palumbi 2010). Varios estudios han mostrado que aquellas especies que no poseen una larva pelágica (i.e., modo de desarrollo directo) tienden a mostrar mayor diferenciación y estructuración genética poblacional que otras especies que la presentan (i.e., modo de desarrollo indirecto), lo que sugeriría un menor flujo genético entre las poblaciones (Cárdenas et al. 2009, Kelly \& Palumbi 2010, Sánchez et al. 2011). El estudio de la relación entre el modo de desarrollo, potencial de dispersión y conectividad poblacional, es importante para entender procesos evolutivos, como la especiación y la extinción, y como apoyo para el desarrollo de medidas y políticas de manejo y conservación de especies marinas.

Crepidula coquimbensis (Lamarck, 1822) es un gasterópodo marino de la familia Calyptraeidae nativo de las costas de Chile, que habita exclusivamente conchas vacías de otros gasterópodos como Tegula euryomphala, T. atra, Xanthochorus cassidiformis y Priene scabra. Se ha descrito solo en la Bahía de La Herradura (2958’32”'S;

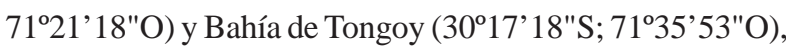
en el norte de Chile, en fondos arenosos entre 2 y $10 \mathrm{~m}$ de profundidad (obs. pers. A. Brante). Como todos los miembros de la familia Calyptraeidae, esta especie es hermafrodita secuencial cambiando de macho a hembra durante su ciclo de vida (Véliz et al. 2003). Los machos y juveniles son móviles, mientras que las hembras son sedentarias e incuban sus cápsulas con embriones (Véliz et al. 2003). De esta forma, machos y juveniles tendrían la capacidad para moverse entre conchas hospederas, mientras que los individuos que se transforman en hembras permanecen definitivamente en la concha hospedera donde ocurrió el cambio de sexo. C. coquimbensis presenta desarrollo directo, donde las hembras incuban sus cápsulas durante todo el desarrollo embrionario de las crías, eclosionando en estado juvenil (Brown \& Olivares 1996, Véliz et al. 2003). Una característica particular de esta especie, es que siempre se encuentra asociada a cangrejos ermitaños de las especies Pagurus edwardsi y P. wedelli. La ausencia de un estado larval dispersante, y la especificidad por su hábitat, podrían dificultar la dispersión y colonización de conchas hospederas, resultando en una alta diferenciación genética poblacional. Por otra parte, el hecho que no se ha encontrado C. coquimbensis en conchas que no están habitadas por cangrejos ermitaños, sugiere que la relación entre ambas especies podría ser determinante para el 
potencial de dispersión de $C$. coquimbensis. Dada estas características biológicas y ecológicas, se postulan las siguientes hipótesis: (1) C. coquimbensis presenta una distancia genética poblacional significativa y (2) la asociación con los cangrejos ermitaños proporciona un medio efectivo para su dispersión y colonización de otras conchas hospederas. Para someter a prueba ambas hipótesis se plantearon los siguientes objetivos: (1) evaluar la diversidad y distancia genética poblacional de C. coquimbensis en tres localidades del norte de Chile y (2) estudiar el rol de P. edwardsi como vector de dispersión de juveniles y machos de $C$. coquimbensis.

\section{MATERIALES Y MÉTODOS}

\section{RECOLECCIÓN DE INDIVIDUOS}

Durante el mes de septiembre del año 2010 se muestrearon las 3 localidades donde se ha registrado Crepidula coquimbensis: muelle de la Universidad Católica del Norte (UCN; 2957'59”'S; 71'21'11”'O); playa Los Bucaneros (LB; 2958’59”'S; 71²1’41”'O), ubicadas dentro de la Bahía La Herradura y distanciadas por $2 \mathrm{~km}$, y la localidad de Puerto Aldea (PA; 30¹1’30”'s; 71²5’24”O) en la Bahía de Tongoy (Fig. 1). Por medio de buceo autónomo, se extrajeron de forma aleatoria alrededor de 100 ejemplares en cada localidad para realizar los análisis genéticos utilizando como marcador el gen COI y los experimentos de dispersión.

\section{DIVERSIDAD Y DIFERENCIACIÓN GENÉTICA POBLACIONAL}

Se analizaron entre 26 y 29 individuos de Crepidula coquimbensis de cada localidad (Tabla 1). La extracción de ADN se realizó a partir de tejido del pie utilizando el método estándar de extracción con sales. Para ello, se extrajo de la musculatura del pie un trozo de tejido de aproximadamente 3 a $4 \mathrm{~mm}$ de longitud, el cual fue cortado en trozos pequeños con una tijera. Luego, se agregó a la muestra $500 \mu \mathrm{l}$ de tampón de lisis (pH 7,5) y $5 \mu \mathrm{l}$ de Proteinasa $\mathrm{K}\left(20 \mathrm{mg} \mathrm{ml}^{-1}\right)$. Esta solución se incubó a $65^{\circ} \mathrm{C}$ por $2 \mathrm{~h}$ agitándola cada $20 \mathrm{~min}$. Posteriormente se adicionó $570 \mu \mathrm{l}$ de $\mathrm{LiCl} 6 \mathrm{M}$ y $230 \mu \mathrm{l}$ de KAc 5M incubando en hielo por $20 \mathrm{~min}$. Las muestras fueron luego centrifugadas a 12000 x g por 15 min y se transfirió $900 \mu$ l del sobrenadante a un nuevo tubo Eppendorf. Se agregó $500 \mu \mathrm{l}$ de isopropanol frío agitando energéticamente. Nuevamente se centrifugó a 12000 x g por 10 min desechando por completo el sobrenadante. Se lavó el pellet con $500 \mu \mathrm{l}$ de etanol $70 \%$. Se centrifugó a 12000 x g por 10 min para nuevamente desechar completamente el sobrenadante. Finalmente, se secó el pellet a $37^{\circ} \mathrm{C}$ por 5 min y se resuspendió en $50 \mu \mathrm{l}$ de agua ultra pura.

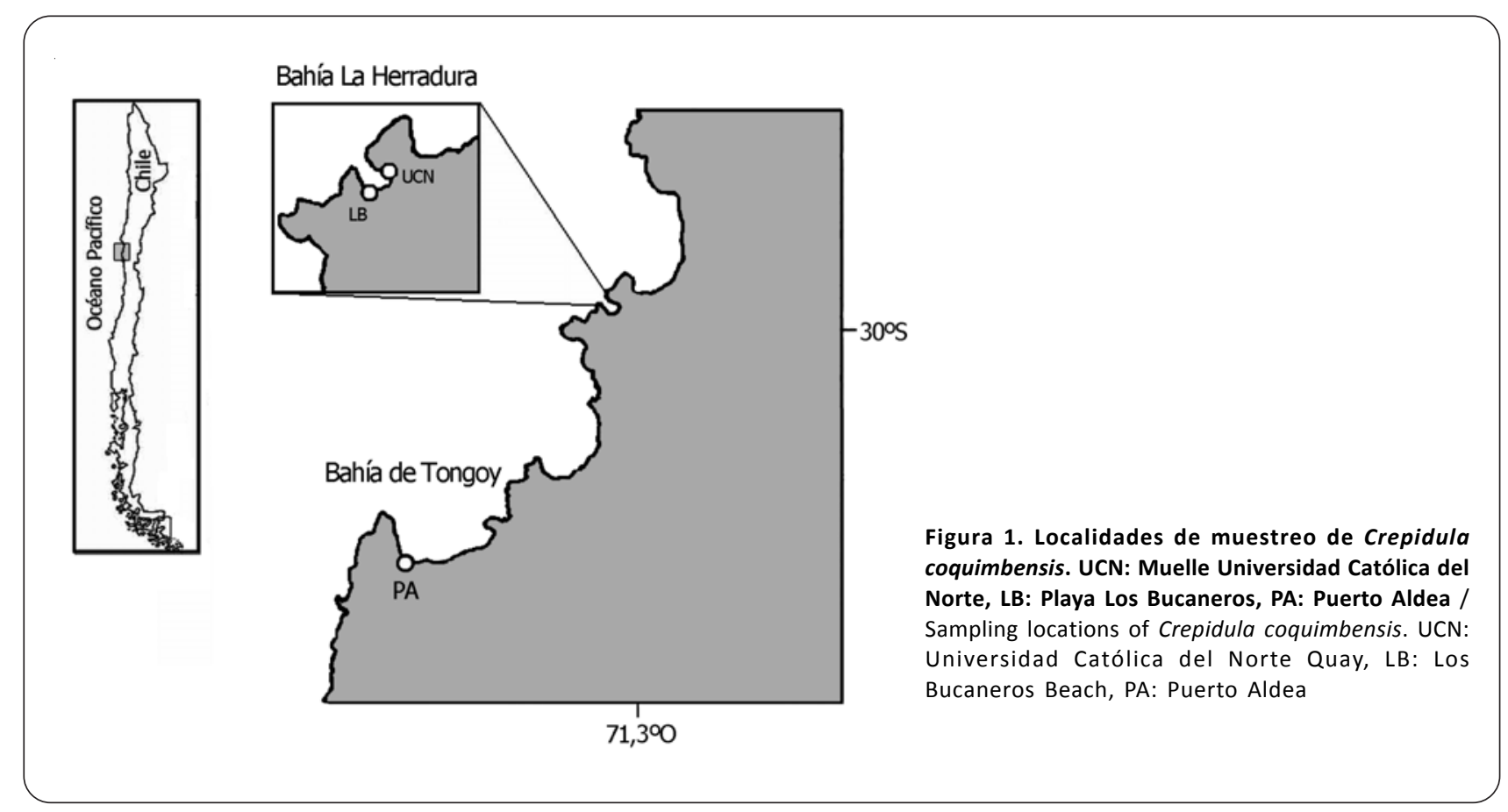


Tabla 1. Diversidad genética del gen mitocondrial COI en Crepidula coquimbensis para 3 localidades del norte de Chile. $\mathrm{N}$ : número de individuos, $\mathrm{Pb}$ : pares de bases, $\mathrm{N}_{\text {hap }}$ : número de haplotipos, $\mathrm{H}_{\mathrm{d}}$ : diversidad haplotípica, $\mathbf{S}$ : sitios segregantes y $\pi$ : diversidad nucleotídica / Diversity of the mitochondrial gene $\mathrm{COI}$ in Crepidula coquimbensis from 3 localities from the north of Chile. $\mathrm{N}$ : number of samples, $\mathrm{Pb}$ : number of base pairs, $\mathrm{N}_{\text {hap }}$ : number of haplotypes, $\mathrm{H}_{\mathrm{d}}$ : haplotype diversity, $\mathrm{S}$ : segregating sites and $\pi$ : nucleotide diversity

\begin{tabular}{lcccccc}
\hline Localidad & $\mathrm{N}$ & $\mathrm{Pb}$ & $\mathrm{N}_{\text {hap }}$ & $\mathrm{H}_{\mathrm{d}}$ & $\mathrm{S}$ & $\pi$ \\
\hline Puerto Aldea & 26 & 626 & 11 & 0,78154 & 15 & 0,00301 \\
Playa Los Bucaneros & 28 & 626 & 6 & 0,33069 & 6 & 0,00081 \\
Muelle Universidad Católica del Norte & 29 & 626 & 5 & 0,62808 & 8 & 0,00167 \\
Total poblaciones & 83 & 626 & 19 & 0,73935 & 26 & 0,00232 \\
\hline
\end{tabular}

Los extractos de ADN de cada muestra teñidos con bromuro de etidio fueron visualizados en geles de agarosa al $1 \%$ en un transluminador UV, por medio del método de electroforesis. La amplificación del gen COI se realizó mediante la reacción en cadena de la polimerasa (PCR), y fueron utilizados los partidores universales HCO1 y LCO1 (Folmer et al. 1994). La amplificación por PCR fue realizada en un volumen final de $10 \mathrm{ml}$ en las siguientes

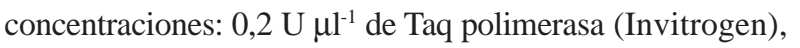
$1 \mathrm{X}$ de buffer de reacción, 0,25 mM dNTPs, 1,5 mM de $\mathrm{MgCl}_{2}$, 1X de BSA, 0,10 $\mu \mathrm{mol}$ de cada partidor $\mathrm{y}$ aproximadamente $6 \mathrm{ng}^{\mathrm{l} \mathrm{l}^{-1}}$ de templado de ADN. El programa de amplificación consistió en una denaturación inicial de 1 min a $94^{\circ} \mathrm{C}$ seguido por 35 ciclos de $95^{\circ} \mathrm{C}$ por $30 \mathrm{~s}, 49^{\circ} \mathrm{C}$ por $55 \mathrm{~s} \mathrm{y} 72^{\circ} \mathrm{C}$ por $1 \mathrm{~min}$ y $30 \mathrm{~s}$, con una extensión final a $72^{\circ} \mathrm{C}$ por $10 \mathrm{~min}$. El producto amplificado fue enviado a Macrogen Inc. (Korea) para su secuenciación, utilizando procedimientos convencionales. Las secuencias fueron editadas y alineadas usando el programa BioEdit 7.0 (Hall 1999).

Para caracterizar genéticamente las poblaciones, se estimaron índices de diversidad genética estándar: número de haplotipos, diversidad haplotípica, sitios segregantes y diversidad nucleotídica. La diferenciación genética se evaluó estimando la distancia genética global y entre localidades con el índice de diferenciación genética $\mathrm{F}_{\mathrm{st}}$, donde 0 indica ausencia de diferenciación genética y 1 indica completa diferenciación. El nivel de significancia de $\mathrm{F}_{\text {st }}$ con respecto a un valor 0 , fue estimado por un procedimiento no paramétrico, utilizando 1000 permutaciones y un valor de probabilidad de 0,05, implementado en el programa Arlequin Ver. 3.1 (Excoffier et al. 2005). La distribución espacial de los haplotipos se investigó construyendo una red de haplotipos con el algoritmo 'vecino más próximo' implementado en el programa Network 4.5.1 (Bandelt et al. 1999). Finalmente, se examinó la historia demográfica y/o selectiva del gen COI calculando la prueba de neutralidad D de Tajima (Tajima 1989) en el programa Arlequin ver 3.1 (Excoffier et al. 2005).

UTILIZACIÓN DE $P$. EDWARDSI COMO MECANISMO DE DISPERSIÓN POR INDIVIDUOS DE C. COQUIMBENSIS

De los individuos recolectados, se clasificaron en juveniles, machos y hembras mediante observación externa bajo lupa de disección del pene en el caso de los machos y vagina en el caso de las hembras (Brown \& Olivares 1996). Individuos sin pene y bajo la talla de $5 \mathrm{~mm}$ fueron considerados juveniles (Véliz et al. 2003).

Se dispusieron 4 conchas hospederas de Tegula atra con Pagurus edwardsi sin Crepidula coquimbensis en un recipiente plástico $(24,5 \mathrm{~cm}$ x 16,0 cm) con agua de mar, aireación constante y arena en el fondo para simular su hábitat natural. Posteriormente, se adicionó una concha hospedera de T. atra con $P$. edwardsi que contenía 4 juveniles de $C$. coquimbensis (media: 4,7 mm; EE: $\pm 3,3$ ). Paralelamente, este protocolo se repitió usando solo conchas hospederas de T. atra sin P. edwardsi para todos los casos. En cada recipiente se ofreció comida (carne de mariscos en conserva) con distribución espacial contagiosa para favorecer que los ejemplares de $P$. edwardsi se agrupasen e interactuaran físicamente simulando la conducta de agregación que se observa frecuentemente en el hábitat natural (obs. pers. A. Brante). El mismo protocolo se repitió con machos de $C$. coquimbensis (media: 5,1 mm; EE: $\pm 4,4$ ). Al cabo de 4 días, se evaluó el porcentaje de conchas hospederas colonizadas por individuos machos y juveniles de $C$. 
coquimbensis. Se realizaron 10 réplicas en cada tratamiento. El porcentaje de conchas colonizadas por juveniles y machos de C. coquimbensis en presencia y ausencia de P. edwardsi al final del tiempo de observación se comparó con la prueba $t$-student. Debido a que no se observó colonización en ausencia de P. edwardsi, estos datos no fueron incluidos en los análisis estadísticos.

\section{RESULTADOS Y DISCUSIÓN}

Se obtuvieron secuencias del gen COI en un total de 83 individuos de las 3 localidades consideradas (Tabla 1). Se observaron 19 haplotipos distintos, siendo la localidad de PA la que presentó el mayor número, seguido por LB y UCN (Tabla 1). Los mayores valores de diversidad haplotípica y nucleotídica, así como el número de sitios segregantes fueron observados en PA y los menores en LB (Tabla 1).

Teóricamente, en especies con poblaciones de tamaño reducido, es esperable una baja diversidad genética producto de la endogamia y mayor efecto de la deriva genética (Wright 1977). La diversidad genética observada en los distintos índices estimados fue similar a la reportada para otras especies de invertebrados marinos con desarrollo directo y que presentan una amplia distribución y alta abundancia frente a las costas de Chile (e.g., Acanthina monodon: Sánchez et al. 2011; Crepipatella dilatata: Guzmán et al. 2011). Este hecho, sumado a los valores negativos y significativos del $\mathrm{D}$ de Tajima global $(\mathrm{D}=-2,3 ; P<0,05)$ en dos de las tres localidades analizadas (UCN: $\mathrm{D}=-1,5 ; P>0,1 ; \mathrm{PA}: \mathrm{D}=-1,8 ; P<0,05 ; \mathrm{LB}: \mathrm{D}=-1.5$,
$P<0,05)$, sugieren que Crepidula coquimbensis presentaría poblaciones de tamaño considerable y en expansión demográfica, siendo probable que esta especie se distribuya en otras localidades no consideradas en este estudio, por lo cual, sería importante realizar muestreos a lo largo de Chile para precisar la distribución y abundancia real de esta especie.

Como regla general, las especies de invertebrados marinos con bajo potencial de dispersión presentan mayor diferenciación y estructuración genética (ver meta análisis de Kelly \& Palumbi 2010). De acuerdo a lo esperado, Crepidula coquimbensis presentó una alta diferenciación y estructuración genética poblacional a escala local (2 km es la distancia aproximada entre UCN y LB). El valor de $F_{\text {st }}$ global para las 3 localidades muestreadas fue estimado en $0,3(P<0,05)$. Los valores de $\mathrm{F}_{\text {st }}$ para las comparaciones pareadas entre localidades arrojaron valores significativos $(P<0,05)$ para todos los casos, con la mayor diferenciación observada entre PA y LB $\left(\mathrm{F}_{\mathrm{st}}=0,34\right)$ y la menor entre UCN y LB $\left(F_{s t}=0,06\right)$; un valor intermedio fue observado entre PA y UCN $\left(F_{s t}=0,27\right)$. De forma similar, la red de haplotipos evidenció una estructuración genética entre las localidades de la Bahía de la Herradura (UCN y LB) y PA. Tres de los 19 haplotipos observados fueron compartidos por 2 localidades, siendo tan solo uno de ellos compartido por localidades de distintas bahías (Fig. 2). Los otros haplotipos derivados de los dos haplotipos más comunes (H1 y H2) fueron exclusivos de las bahías muestreadas (Fig. 2).

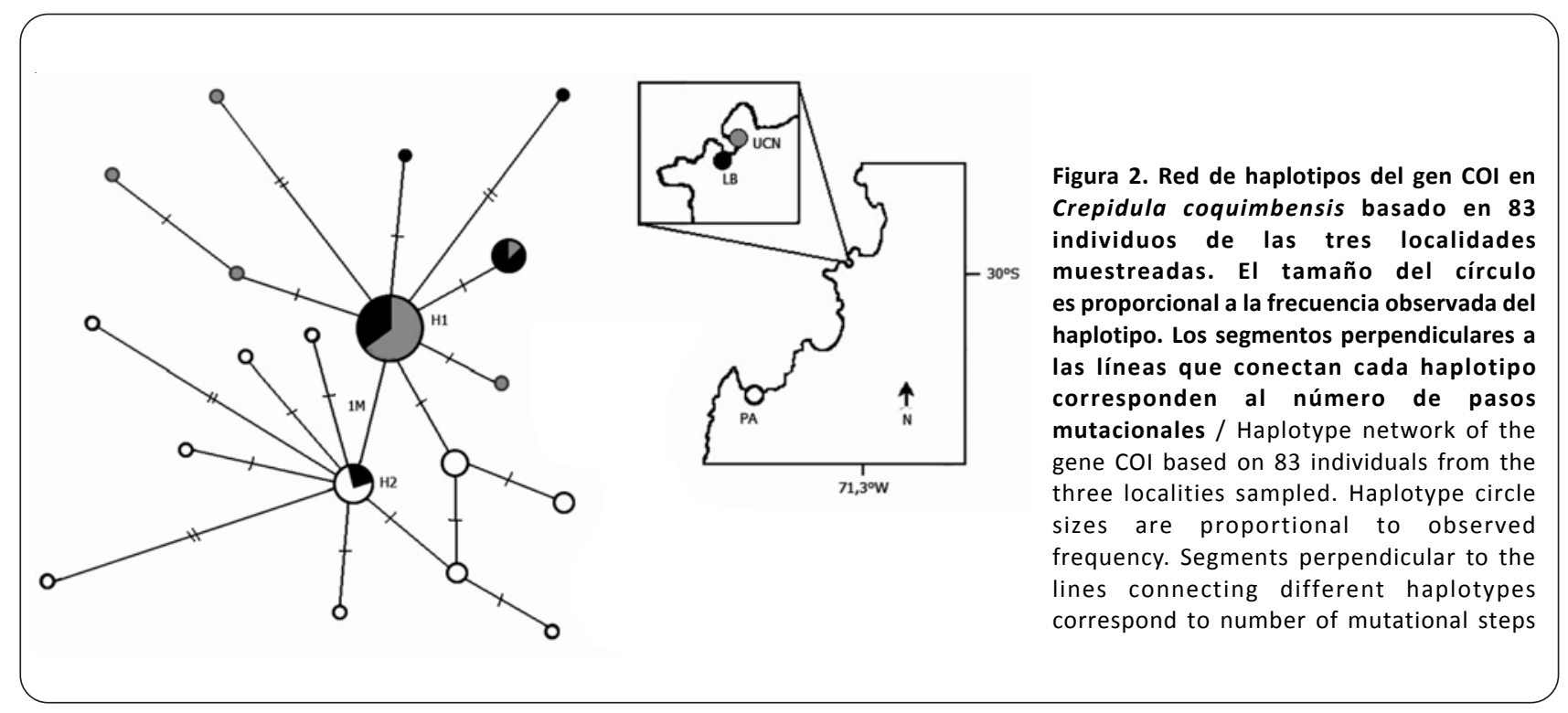


Varias especies sésiles o de baja movilidad utilizan estrategias alternativas para su dispersión (e.g., Thiel \& Gutow 2005). Trabajos anteriores han sugerido que los cangrejos ermitaños son un vector para la dispersión en Crepidula convexa, la cual presenta similares características de historia de vida que Crepidula coquimbensis (Li \& Pechenik 2004). Sin embargo, este sería el primer trabajo que somete experimentalmente a prueba esta hipótesis en el complejo asociativo crepidulacangrejo ermitaño. Los experimentos realizados en el presente trabajo, demostraron que Pagurus edwardsi sería una especie clave en la dispersión de $C$. coquimbensis, no observándose colonización de nuevas conchas hospederas en ausencia del cangrejo ermitaño. En contraste, al finalizar el cuarto día de experimentación, el tratamiento de $C$. coquimbensis en presencia de $P$. edwardsi mostró un porcentaje promedio de colonización de conchas hospederas del 25\% (EE: $\pm 7,9$ ) en juveniles y 15\% (EE: $\pm 6,1)$ en machos, no evidenciando diferencias significativas entre ambos $(t$-student $=1 ; \mathrm{gl}=8 ; P=0,346)$. No se observó mortalidad de machos o juveniles en ninguno de los tratamientos realizados. La estrategia de C. coquimbensis de utilizar la conducta gregaria de los cangrejos ermitaños para dispersarse, podría reducir significativamente el riesgo de mortalidad que conlleva la búsqueda de conchas hospederas de forma aleatoria, incrementando la probabilidad de encontrar conchas hospederas óptimas para su sobrevivencia.

\section{Agradecimientos}

El trabajo fue realizado y financiado completamente bajo el marco del proyecto FONDECYT No 11090221 otorgado a AB.

\section{LITERATURA CITADA}

Bandelt HJ, P Forster \& A Röhl. 1999. Median-joining networks for inferring intraspecific phylogenies. Molecular Biology and Evolution 16: 37-48.

Brown DI \& A Olivares. 1996. A new species of Crepidula (Mollusca: Mesogastropoda: Calyptraeidae) from Chile: additional characters for the identification of eastern Pacific planar Crepidula group. Journal of Natural History 30: 1443-1458.
Cárdenas L, JC Castilla \& F Virad. 2009. A phylogeographical analysis across three biogeographical provinces of the south-eastern Pacific: the case of the marine gastropod Concholepas concholepas. Journal of Biogeography 36: 969-981.

Excoffier L, G Laval \& S Schneider. 2005. Arlequin ver. 3.0: An integrated software package for population genetics data analysis. Evolutionary Bioinformatics Online 1:47-50.

Folmer O, M Black, W Hoeh, R Lutz \& R Vrijenhoek. 1994. DNA primers for amplification of mitochondrial cytochrome c oxidase subunit I from diverse metazoan invertebrates. Molecular Marine Biology and Biotechnology 3: 294-299.

Guzmán BE, JJ Nuñez, A Vejar, EH Barriga \& CS Gallardo. 2011. Genetic diversity and population structure of two South American marine gastropods, Crepipatella dilatata and C. fecunda (Gastropoda: Calyptraeidae): distinct patterns based on developmental mode. Italian Journal of Zoology 78: 444-454.

Hall TA. 1999. BioEdit: a user-friendly biological sequence alignment editor and analysis program for Windows 95/98/ NT. Nucleic Acids Symposium Series 41: 95-98.

Kelly RP \& SR Palumbi. 2010. Genetic structure among 50 species of the northeastern Pacific rocky intertidal community. Public Library of Science ONE 5:e8594.

Li W \& JA Pechenik. 2004. A forced association between the slippersnail Crepidula convexa and the hermit crab Pagurus longicarpus?-possible influence from a third party. Journal of Experimental Marine Biology and Ecology 311: 339-354.

Sánchez R, RD Sepúlveda, A Brante \& L Cárdenas. 2011. Spatial pattern of genetic and morphological diversity in the direct developer Acanthina monodon (Gastropoda: Mollusca). Marine Ecology Progress Series 434: 121-131.

Tajima F. 1989. Statistical method for testing the neutral mutation hypothesis by DNA polymorphism. Genetics 123: 585-595.

Thiel M \& L Gutow. 2005. The ecology of rafting in the marine environment. I. The floating substrata. Oceanography and Marine Biology: An Annual Review 42: 181-264.

Véliz D, FM Winkler \& C Guisado. 2003. Developmental and genetic evidence for the existence of three morphologically cryptic species of Crepidula in northern Chile. Marine Biology 143: 131-142.

Weersing K \& RJ Toonen. 2009. Population genetics, larval dispersal, and connectivity in marine systems. Marine Ecology Progress Series 393: 1-12.

Wright S. 1977. Evolution and the genetics of populations; a treatise, 611 pp. University of Chicago Press, Chicago.

Recibido el 28 de diciembre de 2011 y aceptado el 25 de abril de 2012

Editor Asociado: Gabriela Muñoz C. 